\title{
Progression and Challenges of Medical Treatment in Severe Functional Mitral Regurgitation: Case Report of 41-Year-Old Woman
}

\author{
I Made Sutha Saskara ${ }^{1 *}$, Ida Bagus Rangga Wibhuti ${ }^{2}$, Bagus Ari Pradnyana Dwi Sutanegara ${ }^{2}$ \\ ${ }^{1}$ Faculty of Medicine, Udayana University, Bali, Indonesia \\ ${ }^{2}$ Department of Cardiology and Vascular Medicine, Faculty of Medicine, Udayana University, Bali, Indonesia \\ *Corresponding Author: I Made Sutha Saskara, Faculty of Medicine, Udayana University, Bali, \\ Indonesia, Email: suthasaskara@unud.ac.id
}

\begin{abstract}
Introduction: The management of Mitral Regurgitation that still focuses heavily on surgical procedure, proves a challenge in deprived socioeconomic status.

Case Presentation: We report a case of an asymptomatic forty-one years old woman referred with severe mitral regurgitation. Initial echocardiography shows that the patient has a severe mitral regurgitation. Later she underwent serial of follow-up echocardiography while administered oral medications for three months. In the latest evaluation she was found to have a significant improvement in lesion.

Discussion: Despite the promising result, there is a challenge in early surgical intervention because of the limitation in experienced and advanced surgical centre as a prerequisite. When an adequate facility isn't available, medical treatment could help with the management of the valve insufficiency. However, there is still limited studies regarding the benefit of long-term medical therapy in severe valve insufficiency.

Conclusion: Medical therapy for mitral regurgitation could play a role in a setting where an adequate surgical facility is not available and watchful-waiting approach is assigned to the patient.

Keywords: Mitral Insufficiency; Asymptomatic Mitral Regurgitation; Mitral Valve; Echocardiography; Transthoracic Echocardiography; Transoesophageal Echocardiography; Magnetic Resonance Imaging; Medical Treatment; Valve Repair
\end{abstract}

\section{INTRODUCTION}

Symptoms of Mitral Regurgitation rarely happen in the acute onset of the disease. Symptoms usually develop over time with the progression of left ventricle worsening due to the left ventricle can't compensate for the volume overload or increase in the effective orifice area.[1] Management of Mitral Valve Regurgitation is focused primarily on the repairment of Mitral Valve by surgical procedure, either in asymptomatic or symptomatic patients.[2] As in the deprived socioeconomic population, this is not always the case. A high number of cases and lack of access to adequate surgical facility often present as a challenge for surgical option. However, when surgery is less considered, there is limited evidence regarding medical treatment effectiveness on mitral regurgitation patient. Therefore, we present a case of early diagnoses of an asymptomatic patient that hopefully could provide better insight and understanding in the progress and management of asymptomatic mitral regurgitation patients.

\section{CASe Report}

Forty-one years old woman admitted on referral to our clinic on $12^{\text {th }}$ March 2019 with asymptomatic severe mitral valve regurgitation. The overall condition of the patient is good, wellnourished and in no acute distress. On examination, she was asymptomatic, and we found a 4/6 grade murmur holosystolic best heard at the apex. There was no history of heart or metabolic disease from her family. She denied smoking and only drink alcohol about 1-2 glass over the weekend, about 2-3 cups of coffee a day, and energy drink 1-2 cans a day after she finished her shift. She worked as a pantry cook assistant at a international cruise ship since 2002. History of using any intravenous drug injection denied by the patient. 
Patient was referred to our clinic because a heart murmur was discovered by her on-board ship physician when examining her cough complaint. She later had transthoracic echocardiography on $11^{\text {th }}$ February 2019. Echocardiography result showed Severe Mitral Regurgitation, EF (Ejection Fraction) 60-65\%, Posterior Mitral Valve Prolapse, with P1 Carpentier classification, prolapsed segment is thin and redundant with a torn chordae, and ERO (Effective Regurgitant Orifice) is $1.2 \mathrm{~cm}^{2}$. A chest $\mathrm{X}$-ray and electrocardiogram showed normal finding. She also had complete blood count, urinalysis, lipid profile, and biochemistry blood test. Urinalysis showed blood, protein, and leukocytes. Note that she was having her period when the sample from her urine obtained. Lipid profile showed Hypercholesterolemia with Cholesterol $249 \mathrm{mg} / \mathrm{dL}$ and LDL $168 \mathrm{mg} / \mathrm{dL}$.

We re-evaluate her cardiac condition by transthoracic echocardiography and found a Moderate Regurgitation with good contractility with Ejection Fraction 67\% and Left Atrium Dilation. The patient is advised to have a mitral valve repair process, but the patient was reluctant. The patient then was assigned to watchful-waiting approach and was given treatment of Edoxaban 1x60mg and Digoxin $1 \mathrm{x} 0.25 \mathrm{mg}$ with scheduled for monthly follow-up. However, on $23^{\text {rd }}$ April patient agreed to do a mitral valve repair procedure and was scheduled to undergo routine pre-procedure screening consists of angiography, dental and ENT examination, and transoesophageal echocardiography. Angiography was performed on $2^{\text {nd }}$ May 2019 and showed no abnormality (Figure 1). ENT and dental exam were done on $5^{\text {th }}$ May 2019, on examination caries were found, and Edoxaban was stopped for two weeks then the patient underwent five teeth extraction and scaling on $7^{\text {th }}$ May 2019.

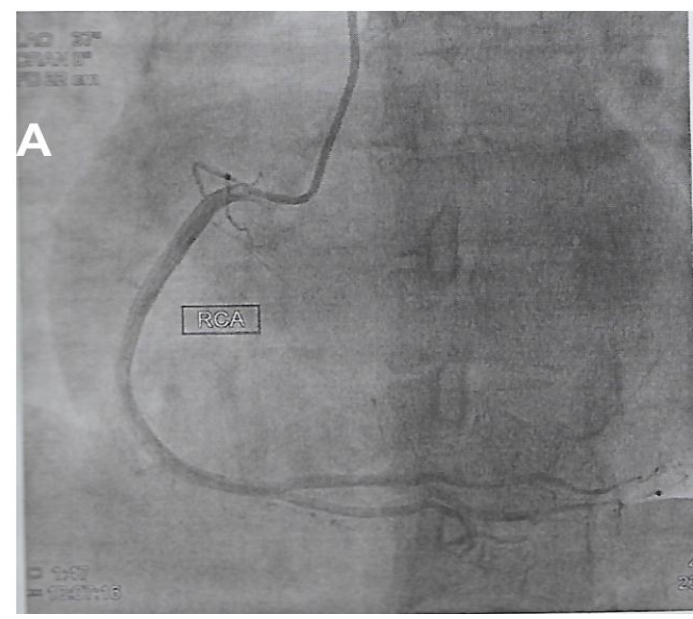

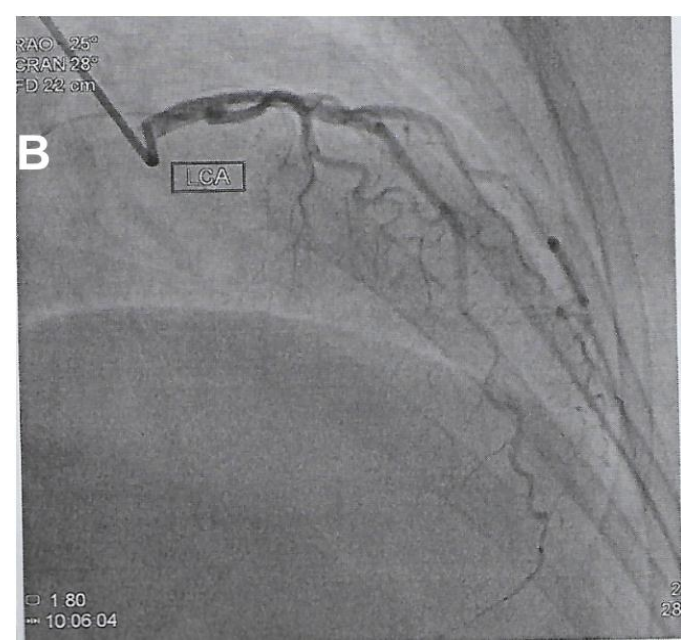

Figure1. Coronoray Angiography on $2^{\text {nd }}$ May 2019. A) Right Coronary Artery (RCA) and B) Left Coronary Artery (LCA) angiography result. Both showed normal coronary with no symptom complained.

Twelve days later on $19^{\text {th }}$ June 2019, transoesophageal echocardiography showed Moderate-Severe Mitral Regurgitation caused by prolapse P1, suspect commissural lesion, normal function of the left systolic ventricle and right ventricle (Figure 2).
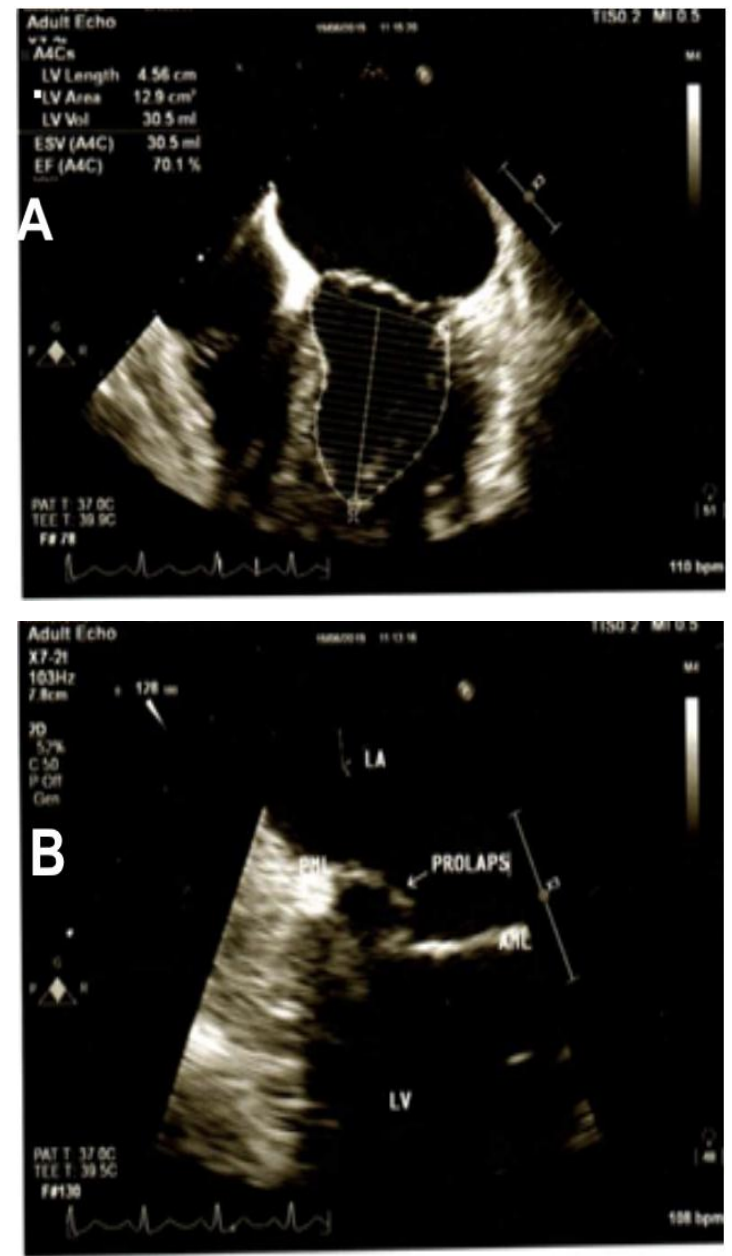


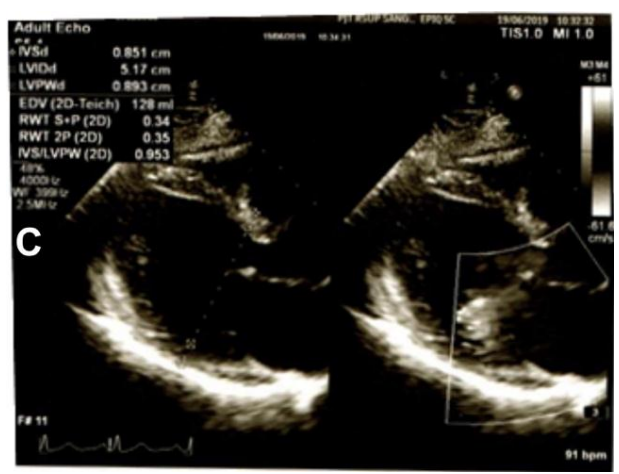

Figure2. Transoesophageal Echocardiography on $19^{\text {th }}$ June 2019 approximately 3 months since patient taking medical treatment for her mitral insufficiency. A) Heart dimension of the patient showed concentric remodeling of left ventricle with normal contractility and systolic function B) Prolapsed P1 from the mitral valve. C) Suspected commissural lesion was detected on transesophageal echocardiography, causing moderate-severe mitral regurgitation $(V C=0.77 \mathrm{~cm}$, $E R O=0.56 \mathrm{~cm}^{2}$, Mitral Regurgitant volume $\left.=71 \mathrm{~mL}\right)$. $V C=$ Vena Contracta $; E R O=$ Effective Regurgitant Orifice.

The patient then given Candesartan 1x8mg and scheduled for a 3D (3 Dimensional) Transesophageal Echocardiography due to the conventional echocardiography limitation in pinpointing the lesion and to reassure the lesion location on the commissural. [Office3] Three Dimensional Transesophageal Echocardiography was done on $23^{\text {rd }}$ July 2019. From the examination, it is found Mild Mitral Regurgitation caused by small perforation at the lateral side of P2 scallop, with normal LV function and contractility (Figure 3). Due to this finding, mitral valve repair surgery was cancelled and the patient continued her treatment consisting of Candesartan. The patient then scheduled for a treadmill test to evaluate maximum exercise capacity. The treadmill test was done three weeks later on $13^{\text {th }}$ August 2019. Treadmill test negative ischaemic response and normal functional capacity and stress test. The patient then scheduled for yearly follow-up or if there are any symptoms that occurred in the future.

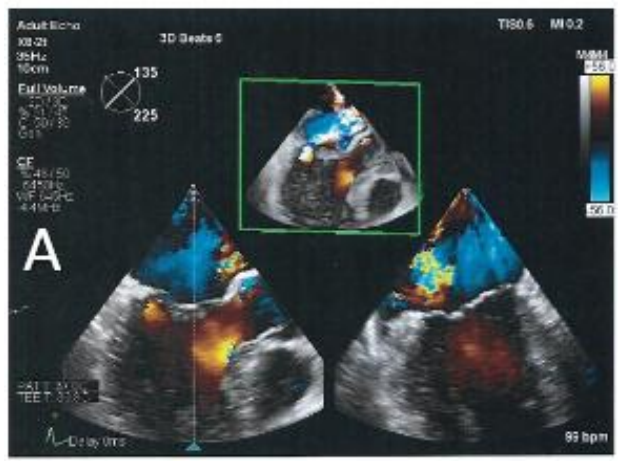

ARC Journal of Clinical Case Reports

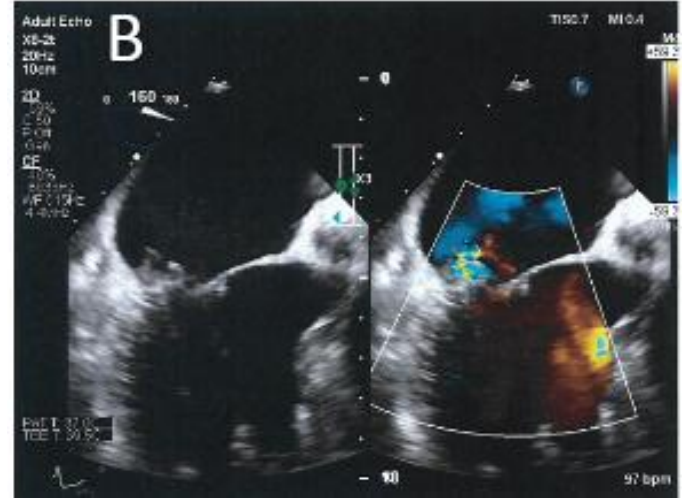

Figure3. Three Dimensional (3D) Echocardiography result on 23rd July 2019. A) Evaluation of heart chambers and function. Right ventricle is dilated with normal systolic function, TAPSE $24 \mathrm{~mm}$. Left ventricle size is normal with Left Ventricle Ejection Fraction (LVEF) $67 \%$ by Simpsons. B) Small perforation at the lateral side of $P 2$ scallop. There is mild regurgitation (PEV $0.9 \mathrm{~m} / \mathrm{s}, \mathrm{VC} 0.3 \mathrm{~cm})$ Pulmonary vein systolic flow is normal.

TAPSE = Tricuspid Annular Plance Systolic Excursion; $L V E F=$ Left Ventricle Ejection Fraction; $P E V=$ Peak Ejection Velocity; VC = Vena Contracta.

\section{DISCUSSION}

This patient had four serial echocardiography with the earliest in February 2019 and the latest in July 2019. The first one in February and reevaluation in March showed the patient had a severe mitral regurgitation. Then transoesophageal was conducted to pinpoint the location of the lesion, and 3D transoesophageal echocardiography provides the additional information for selecting the appropriate repair strategy for this patient. Based on the criteria where surgery is recommended; LVEF $\leq 60 \%$ or LVESD $\geq 45 \mathrm{~mm}$, new onset of Atrial Fibrillation or SPAP > 50mmHg, patient with high likelihood of durable repair, low surgical risk, and presence of risk factors, [3] this patient is considered to be a candidate for surgery because of the finding from previous echocardiography and the relatively young age of the patient.

The 3D transoesophageal echocardiography showed that the patient had mild regurgitation and its location of the lesion in the valve is tricky. It is an unique occasion where a history of loud murmur intensity (4/6 holosystolic murmur) resulted from a mild mitral regurgitation based on 3D Transesophageal Echocardiography evaluation. However, in some cases severe mitral regurgitation could produce a silent murmur, which is challenging to auscultate. Because of these discordance findings between physical and echocardiography, Magnetic Resonance Imaging 
(MRI) could provide a solution for a useful diagnostic tool. MRI is more accurate than echocardiography in assessing the severity of Mitral Regurgitation.[4] MRI showed good accordance when diagnosing mild Mitral Regurgitation, but MRI often shows MR to be less severe in patients that echocardiography showed moderate-severe regurgitation.[4,5]

Although there are still some arguments on management of asymptomatic mitral valve therapy, with the improvement in surgical techniques and outcomes, the early surgical intervention is gaining traction. Goldstone et al. concluded that early surgical intervention might improve patient survival.[3] About 66\% of patients with asymptomatic severe primary mitral regurgitation will undergo surgery in 5 years because of symptoms, left ventricle dysfunction, pulmonary hypertension, or Atrial Fibrillation. Postoperative survival is also better when surgery is performed before the patient becomes symptomatic. However, there is a challenge because a limitation in remote areas because an experienced and advanced surgical centre is a prerequisite to undergo surgical intervention in asymptomatic patients, which often become the main reason in assigning watchful-waiting approach in asymptomatic patient.[3,6]

During the course of the therapy, she was given Edoxaban and Digoxin. Digoxin is a negative inotropic to reduce the pressure in the left chamber of the heart. Digoxin is shown to reduce the symptoms of mitral valve regurgitation.[7] For the thromboembolic event prevention in this patient, anticoagulant was given. In ENGAGE AF-TIMI study, there are 2824 (13\%) patients with history of moderate or severe Valvular Heart Disease (Mitral Regurgitation, the most prominent) included with Valvular Heart Disease were given a high dose of Edoxaban $60 \mathrm{mg}$ daily and a low dose Edoxaban 30mg daily. The result showed the safety and efficacy of Edoxaban did not affect, compared to Warfarin, in a patient with Valvular Heart Disease. [8] Patient with Valvular Disease, however, has a higher risk of death, cardiovascular event, and major bleeding compared to a patient without Valvular Disease history in both groups receiving Edoxaban and Warfarin. [8,9]

Medical treatment could help with treating complications such as heart failure, hypertension, or pulmonary hypertension. Ace inhibitors, betablockers, aldosterone antagonists could play a role in medical therapy of mitral regurgitation. However, there are limited studies regarding the benefit of medical therapy in the long-term period. Poor outcome of mitral regurgitation is associated with the degree of regurgitation, with the poorest outcome when ERO was $\geq 40 \mathrm{~mm}^{2}$ and it should become the main focus of monitoring the patient progression.[10]

\section{CONCLUSION}

The treatment for mitral regurgitation is still heavily focused on the valve repair procedure by surgical. Medical teraphy for mitral regurgitation could prove useful in a setting where an adequate surgical facility is not available. In this case, the patient prognosis prescribed with medical teraphy is excellent, and watchful waiting for the patient is recommended.

\section{ACKNOWLEDGMENT}

The authors would like to thank you Faculty of Medicine, Udayana University, Sanglah General Hospital, and Department of Cardiology and Vascular Medicine for discussion during the development of this study and authorizing this study.

\section{REFERENCES}

[1] Güvenç RÇ, Güvenç TS. Clinical presentation, diagnosis and management of acute mitral regurgitation following acute myocardial infarction. J Acute Dis 2016;5:96-101. https://doi.org/10.1016/j.joad.2015. 11.001.

[2] Baumgartner H, Falk V, Bax JJ, De Bonis M, Hamm C, Holm PJ, et al. 2017 ESC/EACTS Guidelines for the management of valvular heart disease. Eur Heart J 2017. https://doi.org/ 10.1093/eurheartj/ehx391.

[3] Goldstone AB, Patrick WL, Cohen JE, Aribeana CN, Popat R, Woo YJ. Early surgical intervention or watchful waiting for the management of asymptomatic mitral regurgitation: a systematic review and metaanalysis. Ann Cardiothorac Surg 2015;4:220-9. https://doi.org/10.3978/j.issn.2225-319X.2015. 04.01 .

[4] Uretsky S, Gillam L, Lang R, Chaudhry FA, Argulian E, Supariwala A, et al. Discordance between echocardiography and MRI in the assessment of mitral regurgitation severity: A prospective multicenter trial. J Am Coll Cardiol 2015;65:1078-88. https://doi.org/10.1016/j.ja cc.2014.12.047.

[5] Gelfand E V., Hughes S, Hauser TH, Yeon SB, Goepfert L, Kissinger K V., et al. Severity of mitral and aortic regurgitation as assessed by cardiovascular magnetic resonance: optimizing correlation with Doppler echocardiography. J 
Cardiovasc Magn Reson 2006;8:503-7. https://doi.org/10.1080/10976640600604856.

[6] Cao C, Virk S, Wilcox C, Novis E, Wolfenden H. Asymptomatic mitral regurgitation-wait or operate? Ann Cardiothorac Surg 2015;4:397-8. https://doi.org/10.3978/j.issn.2225-319X. 2015. 03.09 .

[7] Anderson SL, Marrs JC. Direct oral anticoagulant use in valvular heart disease. Clin Med Insights Ther 2018;10. https://doi.org/ 10.1177/1179559X17751638.

[8] Giugliano RP, Ruff CT, Braunwald E, Murphy SA, Wiviott SD, Halperin JL, et al. Edoxaban versus warfarin in patients with atrial fibrillation. N Engl J Med 2013;369:2093-104. https://doi.org/10.1056/NE JMoa1310907.
[9] De Caterina R, Renda G, Carnicelli AP, Nordio F, Trevisan M, Mercuri MF, et al. Valvular Heart Disease Patients on Edoxaban or Warfarin in the ENGAGE AF-TIMI 48 Trial. J Am Coll Cardiol 2017;69:1372-82. https://doi.org/10. 1016/j.jacc.2016.12.031

[10] El Sabbagh A, Reddy YNV, Nishimura RA. Mitral Valve Regurgitation in the Contemporary Era: Insights Into Diagnosis, Management, and Future Directions. JACC Cardiovasc Imaging 2018;11:628-43. https://doi.org/10.1016/ j.jcmg .2018 .01 .009

Citation: I Made Sutha Saskara, Ida Bagus Rangga Wibhuti, Bagus Ari Pradnyana Dwi Sutanegara, Progression and Challenges of Medical Treatment in Severe Functional Mitral Regurgitation: Case Report of 41-Year-Old Woman, ARC Journal of Clinical Case Reports. 2019; 5(4): 1-5. doi:dx.doi.org/ 10.20431/24559806.0504001.

Copyright: (C) 2019 Authors. This is an open-access article distributed under the terms of the Creative Commons Attribution License, which permits unrestricted use, distribution, and reproduction in any medium, provided the original author and source are credited. 